\title{
3 Self-report measures of ageism in the workplace
}

\author{
A scoping review
}

Martine Lagacé, Najat Firzly and Alura Zhang

The chapter relies on a scoping review which is an increasingly common approach used for mapping broad themes in relation to volume, nature and key findings on a specific topic. As such, the chapter aims to summarize and analyze existing validated self-reported scales on ageism in the workplace as well as uncover gaps in ageism research. More so, it enables a comprehensive identification of key trends related to how ageism in the workplace is measured, through identifying validated self-reported scales, assessing their scope and psychometric properties. The five-step scoping review framework outlined by Arksey and O'Malley (2005), that includes "study purpose, study identification, screening process, data extraction, collation and summarization of data", was enacted. The scoping review was conducted in accordance with the Preferred Reporting Items for Systematic Reviews and Meta-Analyses (PRISMA) guidelines (Moher et al., 2009).

\section{Introduction}

Populations are rapidly ageing throughout the world (United Nations Department of Economic and Social Affairs, 2017). In Canada for example, individuals aged 65 years old or older, outnumber those aged 14 years old (Statistics Canada, 2017). These demographic trends have an impact on the Canadian workforce where labor shortages are affecting the manufacturing, retail, construction and healthcare sectors (Conference Board of Canada, 2018). Economists argue that the situation is here to stay and imposes on employers to rethink their hiring and retention strategies. Life-long learning and training of employees to build knowledge pipelines could partly address retention. Encouraging the better integration of groups often left outside job markets, such as Indigenous Canadians, new immigrants and older adults, is another way to address labor shortages. However, the latter requires a shift in the way ageing and older adults are perceived in the workplace. For example, although more older Canadians chose to keep working as shown in the latest 2016 census - over 53 percent of men and 38 percent of women aged 65 or older were working in some form in 2015 considerably more than were doing so in 1995 - they still face important barriers. Ageism is among those barriers (Berger and Hodgins, 2012; Malinen and Johnston, 2013; McQuigge, 2017; Posthuma and Campion, 2009).

Kite and Wagner (2002) conceptualize ageism as a combination of - mostly negative age-based stereotypes, attitudes and behaviors. This tripartite model expresses the different channels through which ageism can be expressed, i.e., cognitive, affective and behavioral. For example, an individual may subscribe to negative age-based stereotypes in believing that ageing is mostly a process of decline and become anxious about his/her own ageing process; 
in turn, this may translate into distancing oneself from older adults. In the workplace, employers who hold negative beliefs and attitudes toward older workers may discriminate against them through hiring and retention processes. Harris et al. (2018) have conducted a scoping review of 43 scientific publications describing the most common ageist stereotypes conveyed by employers toward older workers. Results show that while perceived as possessing soft skills and being loyal and reliable employees, older workers are negatively portrayed as being less capable of adapting to change - especially to new technologies - less capable of learning, less competent and less productive than younger workers. In a rapidly changing workplace, employers place a high value on fast learning and multitasking, and associate such skills mainly to younger workers. As such, being perceived as loyal and having soft skills may not suffice to outweigh the detrimental effect of negative stereotypes such as resistance to change, decreased capacity to learn and decreased productivity.

More important, ageist stereotypes often translate into discriminatory practices on the part of employers. Neumark, Burn and Button (2019) designed and implemented a large field experimental study to test how age-based discrimination permeates employment, namely through discrimination at hiring. Based on evidence from more than 40,000 job applications for administrative jobs, submitted by young applicants (aged 29 to 31), middle-aged applicants (aged 49 to 51) or older applicants (aged 64 to 66), results show that, after controlling for confounding variables, middle-aged and older applicants are significantly more discriminated against, with a callback rate 6.3 percent lower than for younger applicants. Findings from this study are particularly important since they reveal the importance of including older workers nearing the normal retirement age when addressing age-based discrimination.

Studies also show that ageism has a negative impact on older workers' well-being. Findings from an empirical study conducted by Peters et al. (2019) among Dutch workers involved the comparison of three groups of workers (those under than 30, those 30 to 49 and those 50 to 67 years old) as for their perceptions of being the target of ageist stereotypes in the workplace. Findings suggest that perceptions of negative age-based stereotyping have a significant and negative effect on older workers' (in this case, those aged 50 to 67) self-perceived employability, which may in turn have an impact on career decisions. Along the same lines, Lagacé et al. conducted studies among Canadian older workers from the healthcare sector show that ageism generates discontent, which in turn, leads to disengagement, lower self-esteem and professional exit (Lagacé et al., 2008, 2010).

In summary, labor shortages in many Organisation for Economic and Co-operation Development (OECD) countries constrain employers to address barriers related to recruitment and retention. Ageism is undoubtedly one of these barriers and, if not countered, may threaten the long-term sustainability of organizations. A first step in addressing ageism is to document and measure how it is expressed in the workplace (through stereotypes and/or discriminatory practices), and how it is experienced by older workers (i.e., how they recognize and react to ageism). The documentation and the measurement of ageism are particularly important, taking into account that this form of discrimination continues to be socially accepted and does not get the same level of public attention as racism and sexism (North and Fiske, 2012). Hence, the goal of this chapter is to identify and critically analyze existing measures of ageism in the workplace. To do so, a scoping review is undertaken.

\section{Design and methodology}

A scoping review is an increasingly common approach used for mapping broad topics in relation to volume, nature and key findings on a specific topic (Plam et al., 2014). 
The current scoping review aims to summarize and analyze existing validated selfreported scales on ageism in the workplace as well as uncover gaps in ageism research. As such, it enables a comprehensive identification of key trends related to how ageism in the workplace is measured, through identifying validated self-reported scales, assessing their scope and psychometric properties. The five-step scoping review framework outlined by Arksey and O'Malley (2005), that includes "study purpose, study identification, screening process, data extraction, collation and summarization of data", was enacted. This scoping review is also in accordance with the Preferred Reporting Items for Systematic Reviews and Meta-Analyses (PRISMA) guidelines (Moher et al., 2009).

\section{Study identification and screening}

During the months of October and November 2019, team members undertook a major online search to identify academic publications that included the word "ageism" in combination with terms related to "scales" and "workplace" (using the operators or and and). A total of six databases (i.e., AARP Ageline, ABI Inform Global, Business Source Complete, Medline (Ovid), PsycInfo, Scopus) were searched with all possible combinations of the three broad terms (and related terms). Databases were selected after consulting with the university librarian as they were the most likely to comprise the majority of non-gray literature on the scoping review topic. A comprehensive search string on "ageism" was initially developed for AARP Ageline and subsequently transferred for searches in five additional databases (i.e., ABI Inform Global, Business Source Complete, Medline (Ovid), PsycInfo, Scopus). To insure rigor, coherence and optimize reproducibility of the process, a track record of all search terms was maintained for each database. The following key words were used: ageis* or (age* $n 3$ (discriminat* or bias* or stereotyp* or prejudic*)); scale* or test* or questionnaire* or assess* or measure* or inventor* or instrument* or evaluat*; work* (depending on the database, the $n 3$ meaning that a certain word could be separated by at least another three words changed). Accordingly, terms were truncated to search multiple prefixes and suffixes (i.e., searching on ageis* would include results for both ageism and ageist). For instance, articles that included an instrument or measure of attitudes or beliefs toward older workers or old employees would have been included in the results. As indicated above, team members also consulted with a university-based librarian to address search methods and database selection.

Results of all searches were entered into the Covidence software program for systematic reviews (Covidence systematic review software, 2017). Results of subsequent steps are illustrated in Figure 3.1, below, based on the PRISMA's flow diagram (Moher et al., 2009). Following an initial phase of removing duplicates $(n=807)$, titles/abstracts $(n=2030)$ were screened to determine inclusion by two independent raters. No contact with authors to identify additional sources was undertaken. Records were divided randomly across raters, and disagreements were resolved through consensus with a third rater.

A total of 1746 titles/abstracts were rated as irrelevant records. Moreover, full-text review ( $n=284$ ) was performed independently by two raters, who resolved disagreements through consensus with a third reviewer. A snowball search was conducted to identify additional records for full-text review by using Google Scholar's "related to" and "cited by" functions for each of the articles included in the original search. 


\section{Eligibility}

Instruments identified throughout the searches were retained for analysis and review if they met the following inclusion criteria: (a) available in English or French; (b) published between 2000 and 2019; (c) aimed to develop/evaluate measurement properties of a quantitative self-reported scale on ageism targeting older adults in the workplace, either from the perspective of the perpetrator or the victim; (d) relied on original research; (e) available electronically in full-text, peer-reviewed; and (f) reported evidence of reliability or validity with different samples. The rationale for this last criterion is that a minimum number of independent studies is needed for the psychometric validation of a scale. In addition, studies that assessed a modified scale to measure ageism (e.g., Ospina, Cleverland and Gibbons, 2019) or included a subscale of ageism, rather than an entire scale, were excluded. Finally, instruments that assessed related but distinct constructs were also excluded.

\section{Data extraction}

Data was extracted from all selected peer-reviewed papers $(n=284)$ and these papers were analyzed by two reviewers. A good number of scales contained in these papers were either modified, had not been validated or were not directly related to ageism in the workplace hence, 117 papers were excluded. In addition, many of these papers relied on a methodology other than self-reported scales or assessed ageism as targeting younger workers and, consequently, were excluded $(n=162)$. Once extraction was completed, researchers reviewed all extraction tables and any discrepancies in data included in various sections, were discussed and resolved. Following the full-text screening stage, five self-reported scales were found to be relevant for the scoping review, according to the six inclusion criteria (see Figure 3.1).

\section{Collation, summarizing and synthesis}

The final step involved a descriptive summary of the scales included in the synthesis through categories analysis. Three main categories of data were extracted: (a) scale characteristics (items and factors, dimensions assessed, language of scale); (b) methodological quality of measurement properties; and (c) number of citations per study in Google Scholar. Table 3.1 summarizes these three main categories. In continuity with Ayalon et al.'s work (2019), seven psychometric properties were assessed in regards to each scale (see Table 3.2): (a) content validity, (b) structural validity, (c) internal consistency, (d) cross-cultural validity, (e) criterion-related validity, (f) convergent validity and (g) discriminant validity.

In the following, a short description of the types of validation is provided. Content validity is determined by asking individuals about the relevance, comprehensiveness and comprehensibility of scale items, response options and instructions. Structural validity relates to the degree to which scores of a scale are an adequate reflection of the dimensionality of the construct measured (Mokkink et al., 2018). On the other hand, internal consistency refers to how well a scale actually measures what it is intending to measure. It also refers to whether the effects observed in a study are due to the manipulation of an independent variable and not to some other variable. Cross-cultural validity aims to determine whether items are similar in different populations (e.g., in different ethnic, gender or language groups). Criterion-related validity (sometimes known as concurrent or predictive validity) relates to the extent to which what is measured by the scale properly, relates to an 


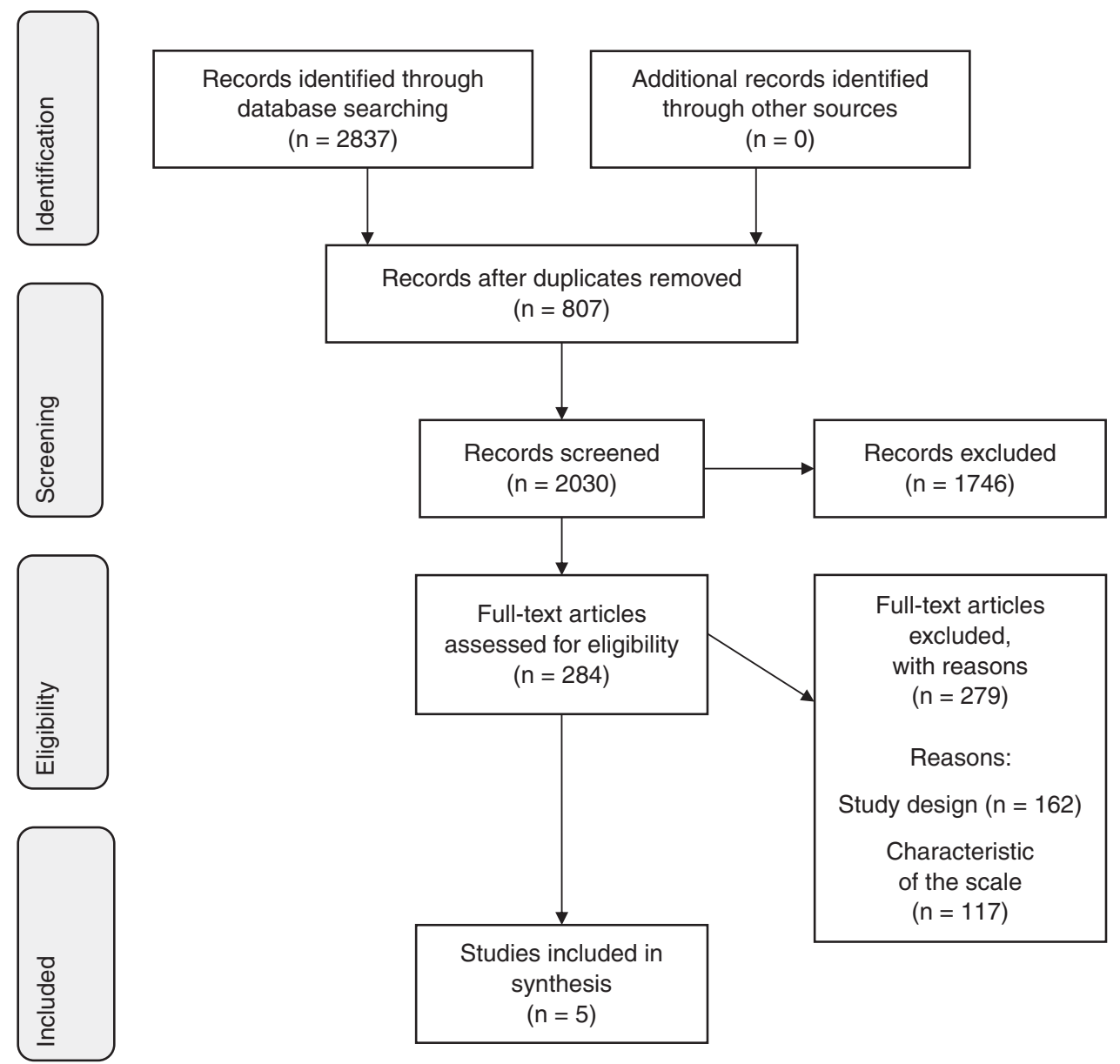

Figure 3.1 PRISMA 2009 flow diagram illustrating the selection of the ageism scales in the workplace.

outcome (McLeod, 2013). In the case of ageism, the outcome could be older workers' level of workplace satisfaction. Convergent validity refers to the degree to which two scales that measure constructs that should be related, are in fact related. Finally, discriminant validity (or divergent validity) allows determination of the extent to which constructs that are not supposed to be related are actually not related.

\section{Results}

Our search methods yielded 2837 abstracts, and a total of five self-reported scales on ageism in the workplace met the inclusion criteria for the current scoping review. The five scales selected for this scoping review are the following: the Workplace Intergenerational Climate Scale (WICS; King and Bryant, 2016); the Nordic Age Discrimination Scale (NADS; Furunes and Mykletun, 2010); the Workplace Age Discrimination Scale (WADS; Marchiondo, Gonzales and Shan, 2016), the Work-related age-based stereotypes scale 


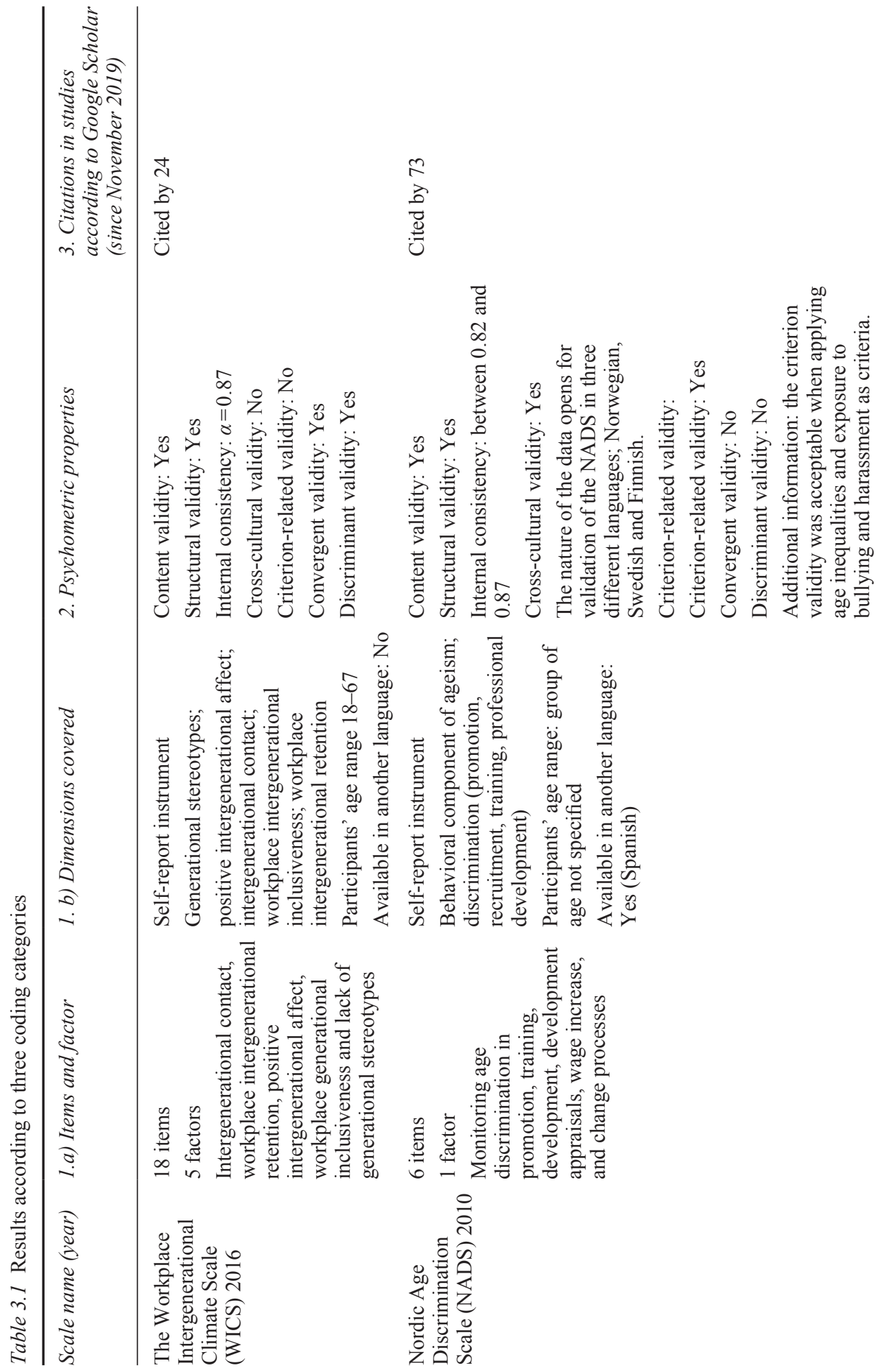


ָ̊

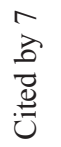

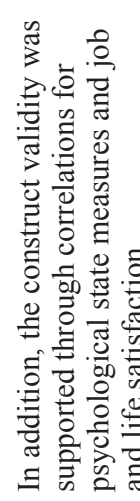

น

离

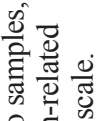

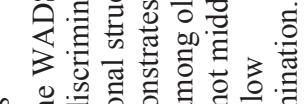

oे

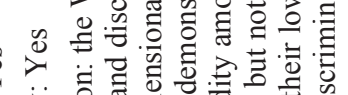

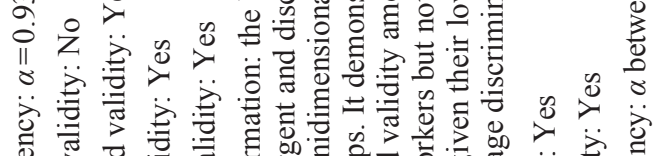

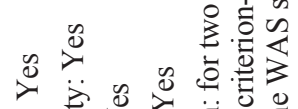

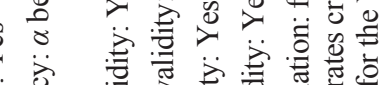

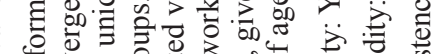

急

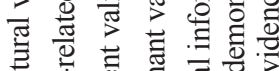

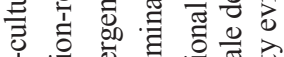

न 8

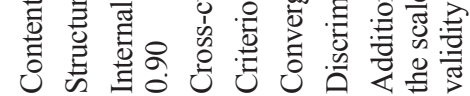
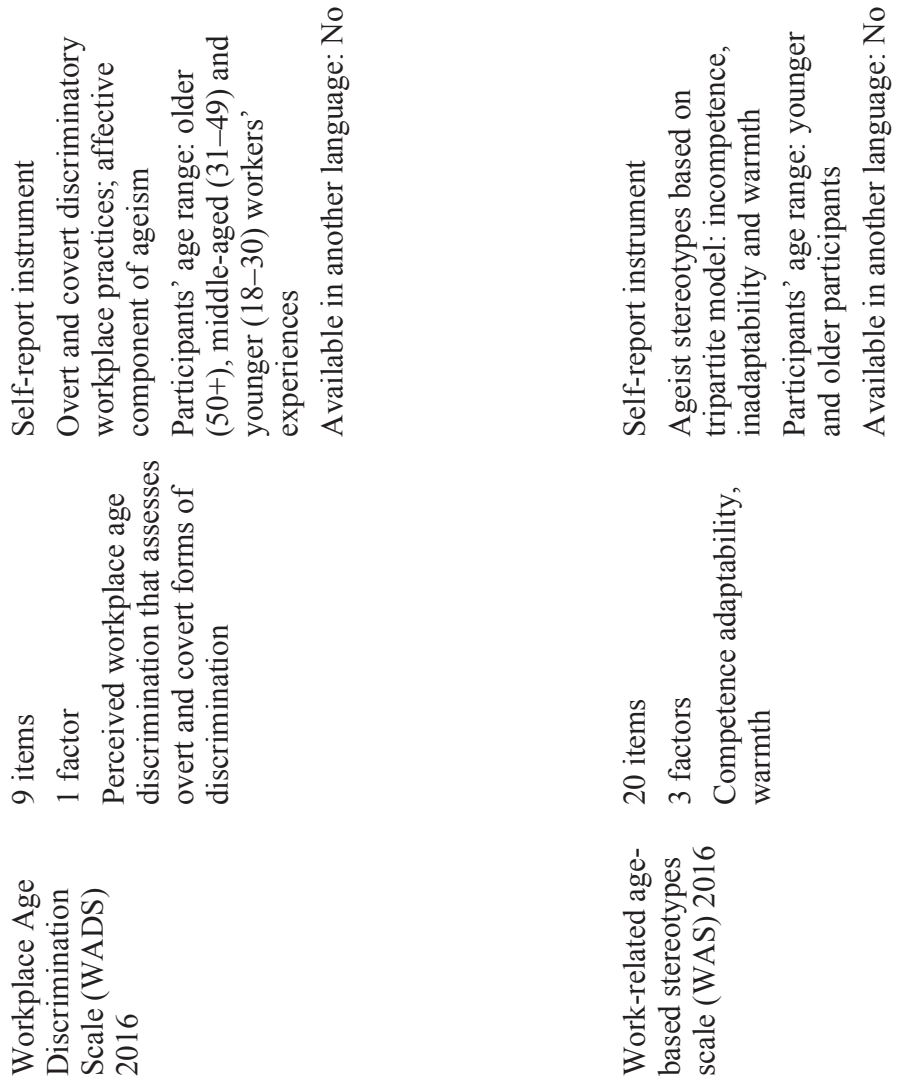


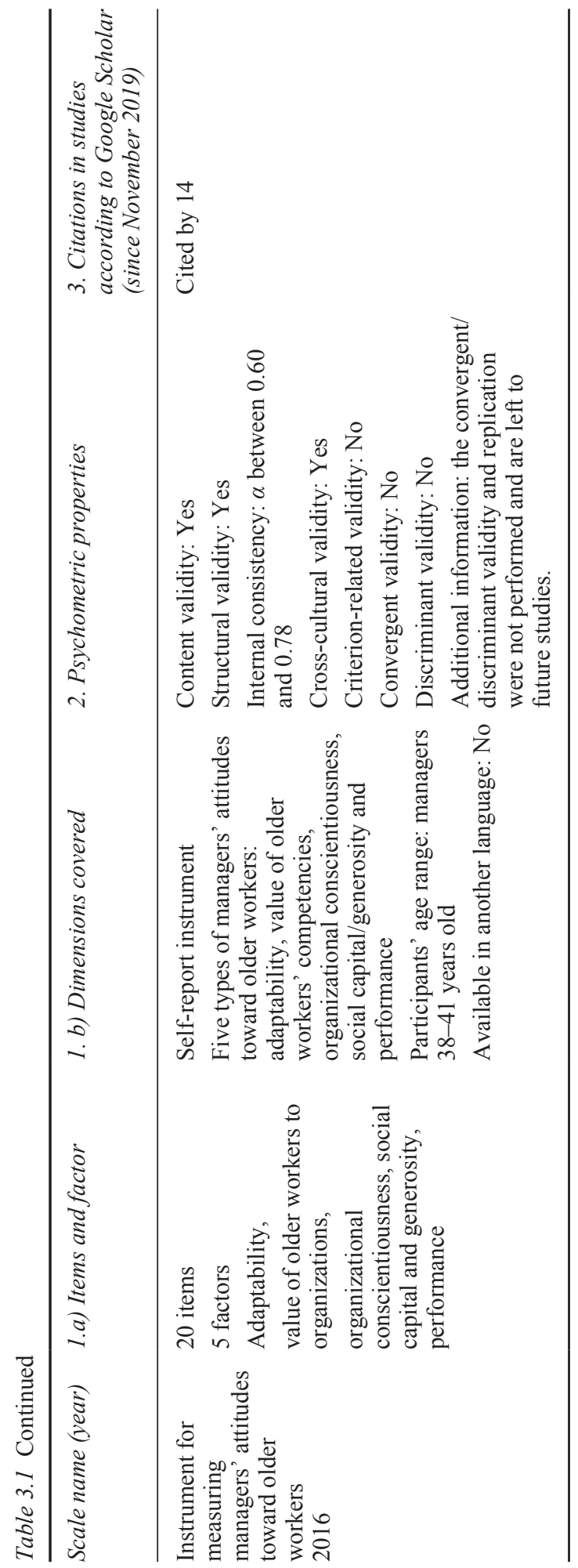


(WAS; Marcus et al., 2016) and the Instrument for measuring managers' attitudes toward older workers (IMAOW; Rego et al., 2016). These scales measure a variety of factors related to ageism, from intergenerational contacts, stereotypes (e.g., competence, warmth, adaptability) to discriminatory workplace practices. Only the NADS has been translated into another language than English (Carral and Alcover, 2019).

Table 3.2 summarizes the aggregated rating of the psychometric properties of each scale as well as overall quality of evidence. Following the COnsensus-based Standards for the selection of health Measurement INstruments (COSMIN) guidelines (Mokkink et al., 2018; Terwee et al., 2018), two independent raters evaluated each scale. Information on discriminant validity was not provided in Table 3.2 since COSMIN does not include a category related to this type of validity. The overall rating of each psychometric property per scale was based on COSMIN, stemming from very good (VG), adequate (A), doubtful (D), inadequate (I) to not applicable (N/A). These criteria were used for all first published versions and first proposed structure of scale (factors and subscales). As COSMIN guidelines require reviewers to conduct their own assessment of the content validity, raters independently assessed the face validity of each scale. To insure reliable judgment, raters examined whether the items included in the scale were relevant to the concept of ageism, whether the items included under each subscale fell into a cohesive domain, as well as whether the phrasing of items and the instructions were easy to understand (Ayalon et al., 2019; Terwee et al., 2018). As shown in Table 3.2, content validity, structural validity, internal consistency, criterion-related validity and convergent validity of these five scales range from acceptable (A) to very good (VG).

\section{Discussion}

This scoping review aimed at understanding how ageism in the workplace is measured and identifying potential knowledge gaps. As stated previously, it is crucial to counteract ageism in the workplace taking into account the rapidly ageing workforce within many nations. Ageism is a barrier that works against recruitment, participation and retention of older workers although these are key factors in addressing labor shortages. The first step in addressing ageism in the workplace is to document its expression and manifestation, notably by measuring it.

This scoping review has allowed the identification of five self-report scales that focus on ageism in the workplace. Although there are a number of other scales targeting ageism in the workplace, these were not included in the review as their psychometric properties, validity and reliability amongst others, have not yet been assessed. Two of the five scales, i.e., the WICS and WADS, address ageism from the perspective of workers who perceive to be the target of age-based stigma, in other words, they measure self-ageism (e.g., "I have been treated with less respect due to my age"). However, both these scales also allow for the measurement of ageism from a multidirectional perspective, i.e., older, middle-aged and younger workers' experiences. Interestingly, the WICS measures employees' attitudes and perceptions about workers of different ages and generations, hence it implies that stereotypes and discrimination may result from prejudiced views in regards to age as well as generations,

On the other hand, the three other scales (NADS, WAS, IMAOW), do not address ageism from the respondents' self-perception and/or experience but more so from an outgroup perspective. Precisely, all items in these scales begin with the statement "Elderly workers ..." or "Older workers ...". As such, when younger, middle-aged and older adults 


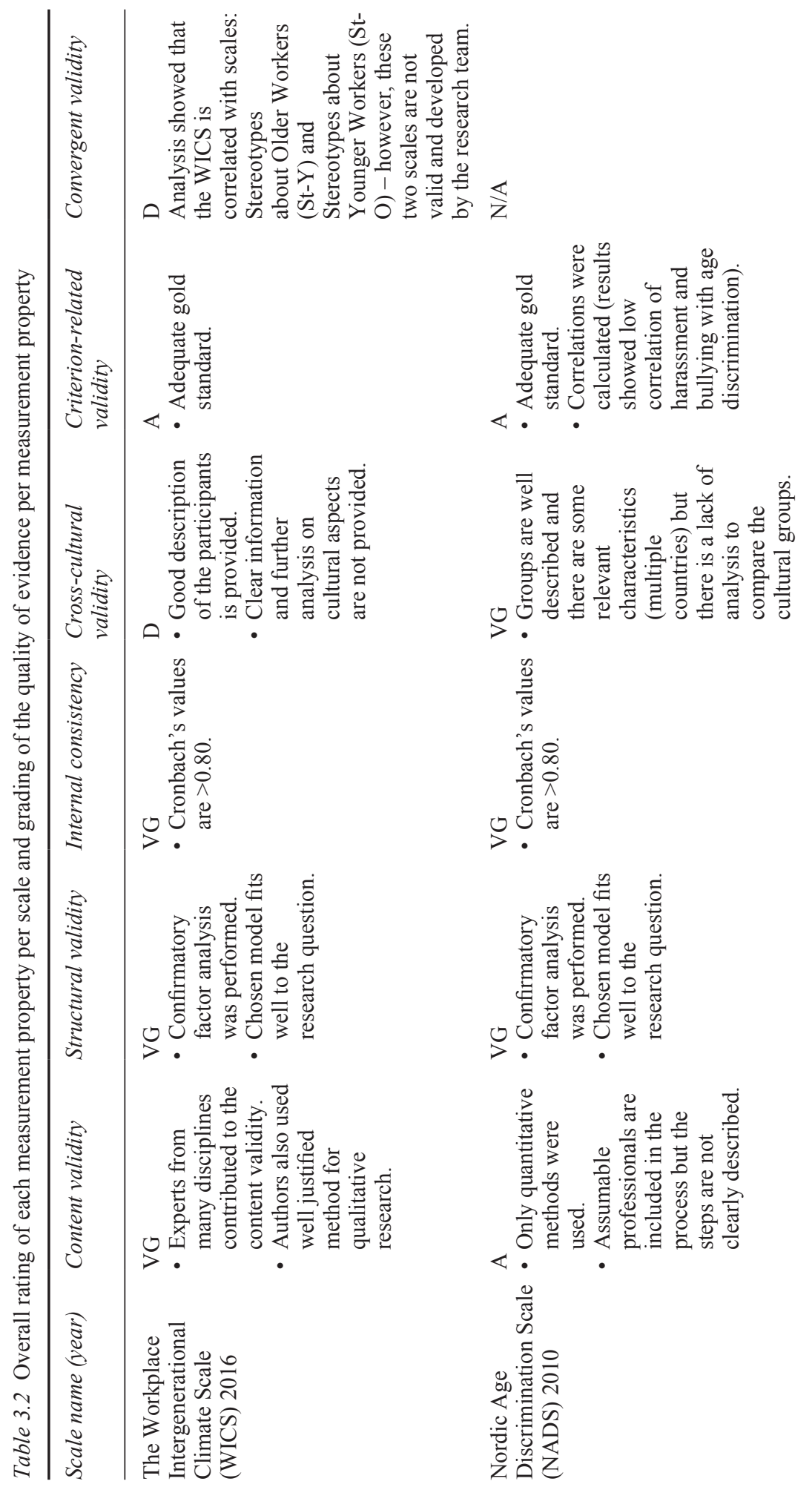



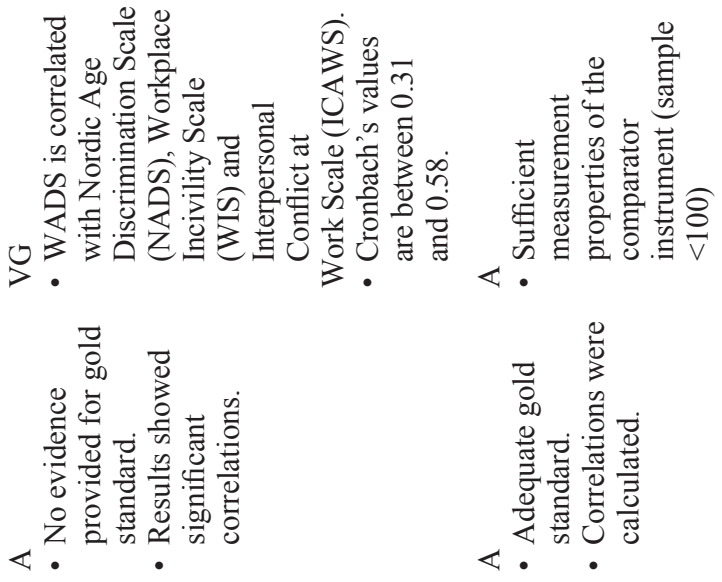

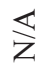
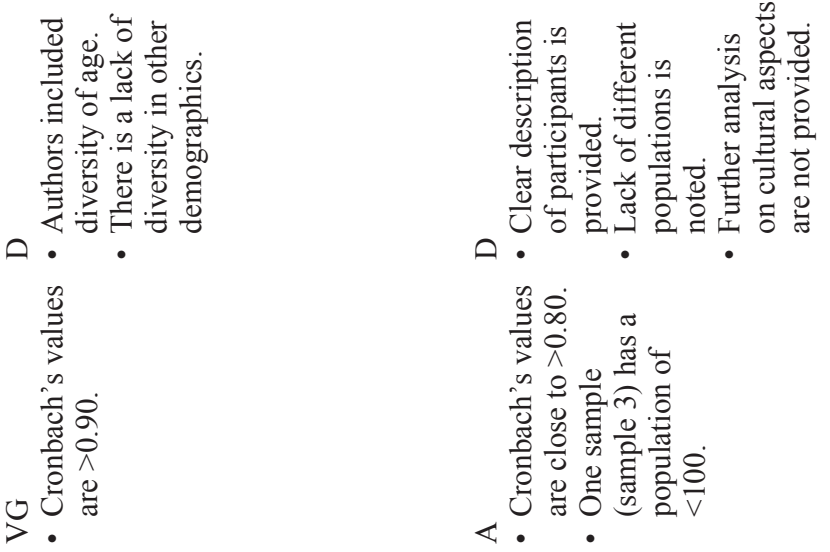

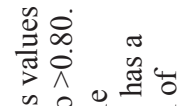
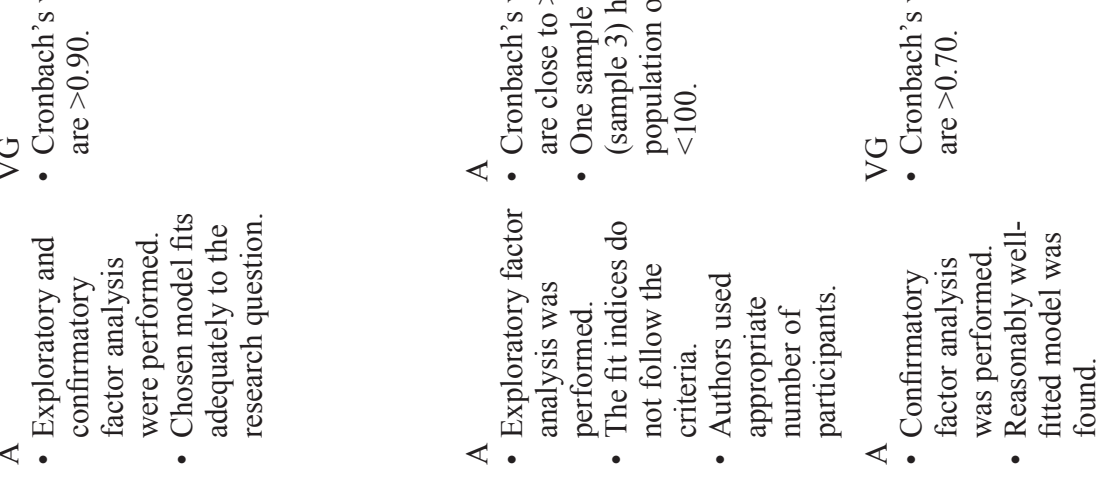

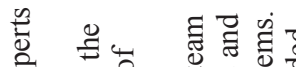

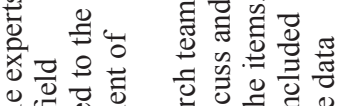

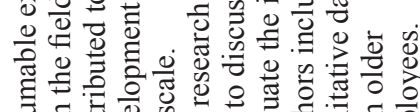

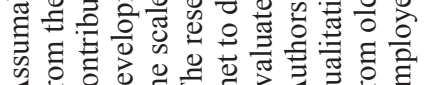

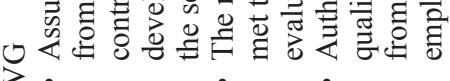
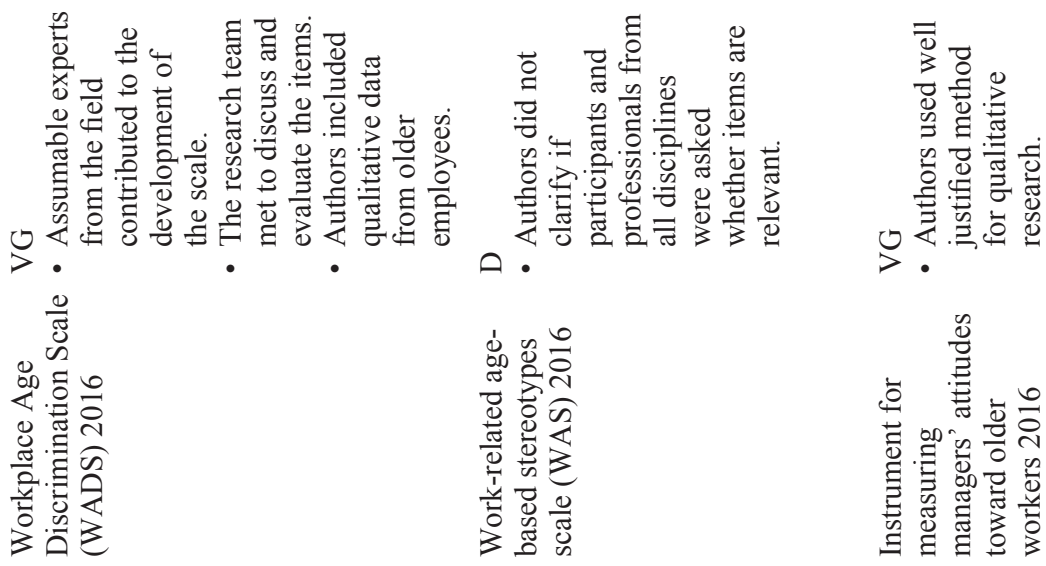
answer these scales questions, they provide their views about elderly/older workers but for the latter group, they may not be thinking of their own experience depending on the extent to which they self-identify as an older adult. Interestingly, as previous studies suggest, some older adults may express negative attitudes toward their peers but view themselves under a more positive, and non-ageist light (Lagacé and Firzly, 2017). Hence, answering questions related to what one considers his or her own experience as an older adult vs that of "other" older adults may yield quite different results. Consequently, when assessing older workers' perception and experience of ageism both a measure related to the "self" and one related to "others" may be more accurate in capturing the complexity of ageism.

Three of the scales included in the scoping review focus on the behavioral component of ageism (WISC, WADS, NADS); in addition, the WADS includes an affective component of ageism (by asking respondents to what extent does each of the stated situations typically bother them). More precisely, the WICS assesses the frequency and quality of contact between workers of the same age and generation as well as of different age and generation. The WADS and the NADS both assess age-based exclusion work practices through recruitment, retention, training, support and promotion processes. In the case of the WADS, overt, in addition to covert, discrimination is measured (with items such as "My contributions are not valued as much due to my age"). On the other hand, the two others scales (WAS and IMAOW) mainly target the cognitive components of ageism, i.e., stereotypes about older workers. Precisely, the IMAOW measures stereotypes related to adaptability, value of older workers' competencies, organizational conscientiousness, social capital/generosity and performance, while the WAS is a three-dimensional stereotype content model including both negative (incompetence, inadaptability) and positive (warmth) stereotypes of older workers. It is interesting to note that the IMAOW assesses how managers perceive older workers and how such perceptions may influence their hiring decisions in terms of selection and training of older workers vs younger workers. The validation of the scale relied on a sample of 224 Portuguese managers and 249 Brazilian managers. Findings reveal that while managers generally attribute positive traits to older workers, they perceive them as having lower adaptability than younger workers (i.e., less able to adapt to new situations and more resistant to change). This finding is in continuity with Posthuma and Campion's (2009) study who have identified the "resistance to change" stereotype about older workers as one of the most prevalent one in the workplace. More so, this stereotype has been found to negatively influence managers' decisions related to hiring and training older workers (Rego et al., 2016).

The five self-reported instruments captured in this review, while revealing acceptable psychometric properties, speak to the need for more research aiming to develop tools to measure ageism in the workplace, especially in regards to managers' perception of older workers. Indeed, findings of studies suggest that manager's decision-making about older workers often relies on ageist stereotypes and attitudes (either conscious or unconscious). For example, as stated in the beginning of this chapter, Neumark, Burn and Button (2019) designed and implemented a large field experiment study to test how age-based discrimination permeates employment, namely through discrimination at hiring. Based on evidence from more than 40,000 job applications for administrative jobs, submitted by young applicants (aged 29 to 31), middle-aged applicants (aged 49 to 51) or older applicants (aged 64 to 66), they found strong evidence of discrimination (i.e., call back rate) against applicants near retirement ages (aged 64 to 66) in comparison to young applicants. Interestingly, workers nearing the normal retirement age (64 to 66 years old) were the ones mostly targeted by discriminatory practices. 
Along the same lines, participation in training is another area where ageist practices on the part of employers have been documented. While life-long learning is one of the means to address an ageing workforce, i.e., by retaining older workers, there is still uncertainty and ambivalence among managers regarding the desirability and feasibility of training older workers. One of the outcomes is that employers generally provide less training to older employees, starting at age 50, than they do to younger employees. Findings from a 2015-2016 study (Lössbroek and Radl, 2019) involving nine European countries and 2517 employees and their managers spread over 228 organizations, confirms the age-based differential treatment. According to Lössbroek and Radl, the reasons for such practices relate to prejudice and stereotypes about ageing in the workplace, where older workers are considered less willing and less able to be trained. Consequently, managers consider the return on investment in training older workers too low. In summary, findings of studies, such as Lössbroek and Radl's, as well as Neumark et al.'s, point to the need for developing more tools to measure managers' views, feelings about ageing and older workers as well as behavioral intentions. In other words, further self-report ageism scales need to be developed that will allow measuring the cognitive, affective and behavioral components of ageism from the perspective of managers. Recruitment and retention of older workers can only happen if managers do not subscribe to ageist stereotypes, express a dislike toward older workers and discard them during recruitment processes and workplace retention initiatives.

Like any form of discrimination, ageism does not exist in a void. A growing number of studies show how ageism intersects with other discriminatory attitudes, including sexism. For example, reinforced by a popular culture that displays ageing women more negatively than ageing men, gendered ageism translates into women being more strongly judged on youth-based physical attractiveness.

In the case of employment, while negative ageist stereotypes may be partially counterbalanced by positive stereotypes that value experience, studies suggest that this appreciation is far stronger for older men than it is for older women. To this effect, Neumark et al.'s, findings not only suggest that the oldest applicants (64 to 66 years old) are targeted by age discrimination in hiring but among those, women are placed at greater risk (Jyrkinen, 2014). To our knowledge, there are no scales that address the differential experience of older female employees in the workplace, or how managers view and treat them.

More generally, there is a need to expand the study of ageism in the workplace using observational, experimental and longitudinal methodologies in addition to self-reported scales. This will allow a better understanding of perceptions related to ageism in the workplace but more importantly of its expressions. Self-reported measures are limited by the threat of social desirability bias and the measurement of behavioral intentions rather than behaviors per se.

\section{Conclusion}

Notwithstanding rapidly ageing populations, ageism remains a prevalent and insidious form of discrimination, one that is under-reported in comparison to racism and sexism. Although ageism can target younger and older adults, the latter are the ones that are primarily the object of age-based stereotypes and discrimination. This is especially the case as relates to older workers who face important barriers stemming from organizational ageist beliefs and practices. Although governments, including the Canadian government, have put in place a number of initiatives to increase the participation and retention of older workers, few of them directly address ageism. However, in the face of current and future labor 
shortages, examining attitudes, notably employers' attitudes toward older workers, is the first step to counteract ageism. Doing so implies that researchers and policymakers can rely on valid instruments that allow measuring implicit and explicit age-based stereotypes and discrimination. The current scoping review has identified five self-reported scales that measure ageism in the workplace, through stereotypes and discriminatory behavioral intentions. Although these scales prove to be reliable, their limited number points to the need for further tools to measure the complexity and multidimensional nature of ageism.

\section{References}

Arksey, H. and O'Malley, L. (2005). Scoping studies: towards a methodological framework. International Journal of Social Research Methodology, 8, 19-32. doi:10.1080/1364557032000119616.

Ayalon, L., Dolberg, P., Mikulioniene, S., Perek-Bialas, J., Rapoliene, G., Stypinska, J., Willinska, M. and de la Fuente-Nunez, V. (2019). A systematic review of existing ageism scales. Ageing Research Reviews, 54, 1568-1637.

Berger, E.D. and Hodgins, D.W. (2012). Policy brief no. 7: age discrimination and paid work. Population Change and Lifecourse Strategic Knowledge Cluster Research/Policy Brief, 1(3), Article 2. Available at: http://ir.lib.uwo.ca/pclc_rpb/vol1/iss3/2 [Accessed 12 July 2019].

Carral, P. and Alcover, C.-M. (2019). Measuring age discrimination at work: Spanish adaptation and preliminary validation of the Nordic Age Discrimination Scale (NADS). International Journal of Environmental Research and Public Health, 16(8), 1431. doi:10.3390/ijerph16081431.

Conference Board of Canada (2018). Global labor market outlook 2018: finding ways to counteract labor shortages. Available at: www.conference-board.org/global-labormarket-outlook-2018/ [Accessed 30 July 2019].

Covidence systematic review software (2017). Veritas Health Innovation, Melbourne, Australia. Available at: www.covidence.org [Accessed 16 July 2019].

Furunes, T. and Mykletun, R.J. (2010). Age discrimination in the workplace: validation of the Nordic Age Discrimination Scale (NADS). Scandinavian Journal of Psychology, 51, 23-30.

Harris, K., Krygsman, S., Waschenko, J. and Laliberte Rudman, D. (2018). Ageism and the older worker: a scoping review. Gerontologist, 58(2), e1-e14. https://doi.org/10.1093/geront/gnw194.

Jyrkinen, M. (2014). Women managers, careers and gendered ageism. Scandinavian Journal of Management, 30(2), 175-185.

King, S.P. and Bryant, F.B. (2016). The workplace intergenerational climate scale (WICS): a selfreport instrument measuring ageism in the workplace. Journal of Organizational Behavior, 38(1), 124-151. doi:10.1002/job.2118.

Kite, M.E. and Smith Wagner, L. (2002). Attitudes towards older adults. In: T.D. Nelson (ed.), Ageism: stereotyping and prejudice against older persons. Cambridge, MA: MIT Press.

Lagacé, M. and Firzly, N. (2017). Who's "really" old? Addressing shifting targets of ageism through in-group and out-group perceptions of ageing. International Journal of Ageing and Society, 7(3), $35-48$.

Lagacé, M., Tougas, F., Laplante, J. and Neveu, J.-F. (2008). La santé en péril: les répercussions de la communication âgiste sur le désengagement psychologique et l'estime de soi des infirmiers de 45 ans et plus. Revue canadienne du vieillissement, 27(3), 285-299.

Lagacé, M., Tougas, F., Laplante, J. and Neveu, J.-F. (2010). Communication âgiste au travail: une voie vers le désengagement psychologique et la retraite des infirmières d'expérience? International Review of Social Psychology, 23(4), 91-121.

Lössbroek, J. and Radl, J. (2019). Teaching older workers new tricks: workplace practices and gender training differences in nine European countries. Ageing \& Society, 39, 2170-2193. doi:10.1017/ S0144686X1800079X.

McLeod, S.A. (2013). What is validity? Simply Psychology. Available at: www.simplypsychology. org/validity.html [Accessed 18 July 2019]. 
McQuigge, M. (2017). More older Canadians choose to keep working, census finds. Canadian Press, 29 November. Available at: www.macleans.ca/economy/more-older-canadians-choose-to-keepworking-census-finds/ [Accessed 18 July 2019].

Malinen, S. and Johnston, L. (2013). Workplace ageism: discovering hidden bias. Experimental Ageing Research, 39(4), 445-465.

Marchiondo, L.A., Gonzales, E. and Shan Ran, E.G. (2016). Development and validation of the workplace age discrimination scale. Journal of Business and Psychology, 31(4), 493-513.

Marcus, J., Fritzsche, B.A., Le, H. and Reeves, M.D. (2016). Validation of the work-related agebased stereotypes (WAS) scale. Journal of Managerial Psychology, 31(5), 989-1004. doi:10.1108/ JMP-11-2014-0320.

Moher, D., Liberati, A., Tetzlaff, J. and Alman, D.G. (2009). Preferred reporting items for systematic reviews and meta-analyses: the PRISMA statement. PLOS Medecine, 6(7), e1000097. doi:10.1371/ journal.pmed1000097.

Mokkink, L.B., Prinsen, C., Patrick, D.L., Alonso, J., Bouter, L.M., de Vet, H.C., Terwee, C.B. and Mokkink, L. (2018). COSMIN methodology for systematic reviews of Patient Reported Outcome Measures (PROMs). User Manual, 78, 1.

Mokkink, L., Terwee, C., Patrick, D., Alonso, J., Stratford, P., Knol, D., Bouter, L. and de Vet H. (2010). The COSMIN study reached international consensus on taxonomy, terminology, and definitions of measurement properties for health-related patient-reported outcomes. Journal of Clinical Epidemiology, 63, 737-745.

Neumark, D., Burn, I. and Button, P. (2019). Is it harder for older workers to find jobs? New and improved evidence from a field experiment. Journal of Political Economy, 127(2), 922-970. www. journals.uchicago.edu/doi/pdfplus/10.1086/701029.

North, M.S. and Fiske, S.T. (2012). An inconvenienced youth? Ageism and its potential intergenerational roots. Psychology Bulletin, 138(5), 582-597.

Ospina, J.H., Cleverland, J.N. and Gibbons, A.M. (2019). The relationship of employment scarcity and perceived threat with ageist and sexist attitudes. Work, Ageing and Retirement, 5(3), 215-235.

Peters, P., Van der Heijden, B.I.J.M., Spurk, D., De Vos, A. and Klaassen, R. (2019). Please don't look at me that way: an empirical study into the effects of age-based (meta-) stereotyping on employability enhancement among older supermarket workers. Frontiers in Psychology, 10(249), 1-14. doi:10.3389/fpsyg.2019.00249.

Plam, M.T., Rajic, A., Greig, J.D., Sargeant, J.M., Papadopoulos, A. and McEwen, S.A. (2014). A scoping review of scoping review: advancing the approach and enhancing the consistency. Research Synthesis Methods, 5(4), 371-385. doi:10.1002/jrsm.1123.

Posthuma, R.A. and Campion, M. (2009). Age stereotypes in the workplace: common stereotypes, moderators, and future research directions. Journal of Management, 35(1), 158-188.

Rego, A., Vitória, A., Miguel, P.C., Tupinambá, A. and Leal, S. (2016). Developing and validating an instrument for measuring managers' attitudes toward older workers. International Journal of Human Resource Management, 28(13), 1866-1899.

Statistics Canada (2017). Portrait de la population active canadienne. Available at: www12.statcan. gc.ca/nhs-enm/2011/as-sa/99-012-x/99-012-x2011002-fra.cfm [Accessed 17 July 2019].

Terwee, C.B., Prinsen, C., Chiarotto, A., de Vet, H., Bouter, L.M., Alonso, J., Westerman, M.J., Patrick, D.L. and Mokkink, L.B. (2018). COSMIN methodology for assessing the content validity of PROMs: user manual. Available at: www.cosmin.nl/wp-content/uploads/COSMINmethodology-for-content-validity-user-manual-v1.pdf [Accessed 17 March 2010].

United Nations Department of Economic and Social Affairs (2017). World population ageing. Available at: www.un.org/en/development/desa/population/publications/pdf/ageing/WPA2017_Highlihts.pdf [Accessed 12 July 2019]. 